\title{
Infecciones de vías urinarias como factor de riesgo en embarazadas multíparas del centro de salud Siete de Octubre del cantón Quevedo, Ecuador
}

\author{
Urinary tract infections as a risk factor in multiparous pregnant women in the parish of Siete de \\ Octubre, Quevedo, Ecuador
}

\begin{abstract}
Lourdes Maribel Bello Carrasco ${ }^{1 *}$, Delia Yulibeth Vélez Rodríguez², Edward Alexis Domínguez Olmeda ${ }^{3}$, Estelia Laurentina
García Delgado ${ }^{1}$, Miryam Patricia Loor Vega ${ }^{1}$
\end{abstract}

\begin{abstract}
RESUMEN
Objetivo: Identificar los principales factores de riesgo de la infección de las vías urinarias en las embarazadas multíparas, y determinar la correlación entre las infecciones de vías urinarias y las complicaciones en las embarazadas. Materiales y Métodos: El método utilizado fue descriptivo transversal. La población comprendida por 436 mujeres embarazadas, del centro de salud "Siete de Octubre", dando como muestra luego de aplicar la fórmula de probabilidad con un 5\% de error de 204 pacientes que fueron encuestadas. Resultados: El 55\% índico que 1 vez al día realiza el aseo íntimo, $76 \%$ manifestaron que con mucha frecuencia se aguanta las ganas de orinar más que todo cuando no se encuentran en sus hogares; $42 \%$ de las mujeres embarazadas manifestaron que las medidas preventivas o tratamientos que ha realizado cuando presenta infección de las vías urinarias es la utilización de remedios caseros, $71 \%$ de las mujeres embarazadas indicaron que si algunas veces han tenido que abandonar el cuidado y tratamiento de la infección de vías urinarias por la escasez de recursos económicos, el $69 \%$ de las mujeres embarazadas no conocen cuales son las principales causas por la que se genera las infecciones y un $100 \%$ de las mujeres, indicaron que si participarían en capacitaciones para conocer los métodos de prevención de la patología. Conclusiones: Se deben establecer estrategias educativas comunitarias orientadas a las mujeres embarazadas del centro de salud Siete de Octubre del cantón Quevedo para disminuir el índice de pacientes embarazadas multíparas con infecciones en la vías urinarias.
\end{abstract}

Palabras claves: Embarazo, infección, riesgo, complicaciones

\begin{abstract}
Objective: To identify the main risk factors for urinary tract infection in multiparous pregnant women and to determine the correlation between urinary tract infections and complications in pregnant women. Materials and Methods: The method used was cross-sectional descriptive. The population comprised of 436 pregnant women, from the health center "Siete de Octubre", showing after applying the probability formula with a 5\% error of 204 patients who were surveyed. Results: $55 \%$ of the indicated individuals, who once per day performed the intimate toilet, $76 \%$ stated that they frequently withstand the urge to urinate more than anything when they are not in their homes; $42 \%$ of pregnant women stated that the preventive measures or treatments they have performed when they have urinary tract infections are the use of home remedies, $71 \%$ of pregnant women indicated that if they have sometimes had to abandon the care and treatment of Urinary tract infection due to the scarcity of economic resources, $69 \%$ of pregnant women do not know the main causes of infection and 100\% of women, they indicated that if they participated in training to know the Methods of prevention of pathology. Conclusions: Community educational strategies aimed at pregnant women should be established at the Siete de Octubre health center in Quevedo, to reduce the rate of multiparous pregnant patients with urinary tract infections.
\end{abstract}

Keywords: Pregnancy, Infection, Risk, Complications

\footnotetext{
${ }^{1}$ Docentes de asignaturas especializadas en Enfermería. Facultad de Enfermería. Universidad Laica Eloy Alfaro de Manabi. Ecuador.

${ }^{2}$ Enfermero. Distrito de Salud 13 D02 CS Divino Niño. Ecuador.

${ }^{3}$ Docente de asignatura de Química y Biología. Responsable del área de Salud. Colegio Juan Montalvo anexo a Universidad Laica Eloy Alfaro de Manabí. Ecuador.
} 


\section{INTRODUCCIÓN}

A nivel mundial las infecciones de vías urinarias son consideradas como las complicaciones médicas que más concurrencia se evidencia durante la gestación además, pueden generar complicaciones importantes tanto para la madre como en el desarrollo del embarazo. Se establece que las infecciones en las vías urinarias pueden afectar entre un margen del $5-10 \%$ de total general de los embarazos. En el centro de salud Siete de octubre la mayoría de mujeres embarazadas multíparas presentan infección de las vías urinarias (IVU) considerando como una condición en la cual las bacterias se instituyen y reproducen en cualquier sector del tracto urinario, generando daños directo o secundario también a la respuesta inflamatoria.

Asimismo, es evidente en varias mujeres donde prevalecen ciertos factores que inducen a la IVU, entre ellos la vida sexual activa, susceptibilidad anatómica, vaciado incompleto de la vejiga y, por último, la deficiencia de estrógenos. Si a estos componentes se suman los cambios fisiológicos en la etapa gestacional donde existe una disminución del tono uretral, disminución del peristaltismo uretral e escasez temporal de las válvulas vesicoureterales, esto incrementa el nivel de riesgo de padecer infección de las vías urinarias durante el proceso de embarazo multíparas. Con este estudio se determina la incidencia de las infecciones de vías urinarias como factor de riesgo de complicaciones en embarazadas multíparas. Las infecciones de vías urinarias, que está evidente desde el inicio de la formación del bebé, puede tener síntomas dependiendo del tipo de infección de vías urinarias generando complicaciones durante el proceso del parto en la madre e recién nacido.

En el Ecuador, los cuidados obstétricos y neonatales esenciales (CONE), son un conjunto de atenciones a las cuales deben tener acceso todas las mujeres embarazadas, puérperas y los recién nacidos, que son fundamentales para salvar las vidas de madres y recién nacidos. La estrategia CONE consiste en asegurar que todas las madres y recién nacidos tengan acceso las 24 horas de día los 365 días del año, a los cuidados obstétricos esenciales de calidad. En Ecuador alrededor del 20\% de las embarazadas han presentado alguna forma de infección de vías urinarias, lo que conlleva a contracciones uterinas momento en el cual es cuando muchas pacientes tienen su primer control prenatal. Todo esto ha llevado a hospitalización para un tratamiento protocolizado de la paciente lo que influye directamente el ámbito psico -emocional de la paciente. (Paredes. M 2008).
Dalet y Del Rio (1998) manifestaron la infección de vías urinaria se define como la invasión microbiana del aparato urinario con mayor frecuencia en mujeres que sobrepasa la capacidad de los mecanismos de defensa de huésped, produce alteraciones morfológicas o funcionales y una respuesta inmunológica no siempre evidenciable.

Por otro lado las infecciones de las vías urinarias pueden limitarse a la vejiga causando, de esta manera una enfermedad llamada cistitis o, con menor frecuencia, afectar también las vías urinarias superiores y, cuando existe una complicación, puede ocasionar hasta pielonefritis aguda, aunque no siempre se descubre en la historia un proceso agudo precedente. Muchas embarazadas tienen bacteriuria asintomática, que es una causa frecuente de pielonefritis aguda en el embarazo.

Ahued, Del Castillo y Bailón (2003). Sostuvieron que los factores de riesgo mientras más alto es el estatus socio-económico, la frecuencia de infecciones urinarias en el embarazo es mucho menor, debido a las posibilidades de especialidad que posee y reciben un tratamiento adecuado. Por el contrario, pacientes con carencias nutricionales o hábitos deficientes de higiene pueden adquirir infecciones urinarias con mayor facilidad y la evolución puede ser más severa.

También la edad y la paridad influyen; ya que la prevalencia de bacteriuria en las multíparas de 35 años también se considera como un factor causal de la frecuencia de infecciones de vías urinarias.

Kavoussi y Parting (2008), refirieron que las complicaciones asociadas con bacterias, durante el embarazo en la era pre antibiótica las mujeres embarazadas con infección urinaria sintomática y pielonefritis bacteriana tenían mayor incidencia de prematuridad, bajo peso al nacer y muerte. La relación entre la bacteriuria asintomática y la prematuridad es menos clara no hallaron diferencias en la evolución del embarazo entre las pacientes tratadas, debido a bacteriuria asintomática y los controles sin bacteriuria, ya que de alguna manera es un causal importante de saber que tratamiento sería el más indicado para corregir de manera temprana este problema y así se disminuiría la alta incidencia de morbimortalidad infantil.

Al respecto, Ahued. Del Castillo, Bailón (2003), aporta con que las infecciones del tracto urinario no son la excepción a esta regla. Las tres complicaciones señaladas con mayor frecuencia son: el parto pre término, la corioamnionitis y la muerte fetal. Con menor frecuencia y en la relación con las pielonefritis seve- 
ras, se señalan la hipertensión arterial y el síndrome de insuficiencia respiratoria. Después del parto, las infecciones urinarias del embarazo aumentan la cifra de endometritis puerperal. Por tal razón se consideran los estudios importantes en mujeres en edad gestacional y controles frecuentes para detectar a tiempo complicaciones futuras.

El embarazo en mujeres que ha dado a luz muchas veces se denomina multípara. Se considera de nulípara, si no ha tenido ningún embarazo, y de gran multípara si ha tenido muchos partos (más de cuatro o cinco). $\mathrm{Si}$ los embarazos y partos antepuestos se han desarrollado normalmente, la multiparidad es un componente muy providencial para el progreso del embarazo y del parto en curso; se establece que la pelvis ya ha pasado varias pruebas. Por lo tanto en el trabajo del parto le facilita su expulsión sin complicaciones.

La etiología de infecciones urinarias son las bacterias como la Echerichia coli o colibacilo es el germen más habitual en los uro cultivos de la pacientes afectadas de infección urinaria extra hospitalaria, y las infecciones en las embarazadas no son una excepción a dicha aseveración. La incidencia oscila entre el 75 y 90. Con mucha menor frecuencia se encuentra Proteus (3-3.5\%) y Klebsiella (1,7-6\%). Aun menos frecuente son Enterobacter, Enterococo, Estreptococo B Y Estafilococo. La responsabilidad del Estreptococo $\mathrm{B}$ ha sido cuestionado, pues su presencia en los uro cultivos podría traducir la contaminación de la muestra de orina por un germen vaginal, pero parece ser que sí podría ser el responsable directo de algunas infecciones urinarias en el embarazo; por esta razón se sugiere una medidas asépticas adecuada al momento de recolección de orina, para obtener una respuesta positiva con valores directamente de la muestra estéril. (Cabero, Zaldívar \& Cabrillo. 2007).

Asimismo, la bacteriuria asintomática es una de las complicaciones infecciosas más frecuentes del embarazo. La prevalencia de la bacteriuria no cambia con el embarazo y oscila entre el 2 y el $7 \%$. El riesgo de adquirir bacteriuria durante el embarazo aumenta con su duración, la clase socioeconómica más baja, la multiparidad y la anemia drepanocitica. Es probable que el origen de la bacteriuria en las pacientes embarazadas refleje la situación antes de la concepción. Según las estadísticas la incidencia de infecciones de vías urinarias en su mayoría se da por un proceso infeccioso, siendo esta la causa de complicaciones. (Kavoussi \& Parting, 2008).
Por tanto, el estado de la mujer que va desde la fecundación hasta el parto o nacimiento, en el fondo, es el período del desarrollo del huevo en el vientre materno y termina con la expulsión del producto. Se sostiene que si el feto es viable, se estaría frente a un parto, y la expulsión de un feto no viable se trataría de un aborto. Razón que prueba hechos evidentes por las semanas gestacionales. (Gonzáles, Ferreira, 2005).

Dentro de la anatomía del sistema genito urinario los uréteres son un par de conductos que transportan la orina desde la pelvis renal hasta la vejiga urinaria. La orina circula por dentro de los uréteres gracias a movimientos peristálticos. La longitud de los uréteres en el adulto es de 25 a 35 centímetros y su diámetro de unos 3 milímetros; por lo tanto, la incidencia se daría porque el uréter de la mujeres es más corto que del hombre lo que hace más factible las infecciones de vías urinarias.

Por tal motivo, este estudio tiene como objetivo principal determinar las infecciones en las vías urinarias como factor de riesgo de complicaciones en las embarazadas multíparas de la parroquia Siete de Octubre del cantón Quevedo. La importancia del estudio radica en establecer las causas principales y los efectos que genera esta bacteria en los pacientes, cuál es el tratamiento más eficiente que se debe seguir, a fin de poder fomentar métodos de prevención y disminuir el índice de pacientes embarazadas multíparas con infecciones en la vías urinarias.

\section{MATERIALES Y MÉTODOS}

El método utilizado fue descriptivo transversal. Participaron 436 mujeres embarazadas, según datos del centro de Salud "Siete de Octubre", dando como muestra luego de aplicar la fórmula de probabilidad con un $5 \%$ de error de 204 pacientes que fueron encuestadas.

Se realizó encuestas y entrevistas aplicadas en el hospital en un tiempo de 180 días donde se determinó lo siguiente: al preguntarles sobre identificación de los principales factores de riesgo de la infección de las vías urinarias en las embarazadas multíparas también se realizó el diagnostico la correlación entre las infecciones de vías urinarias y las complicaciones en las embarazadas para lograr establecer estrategias educativas comunitarias orientadas a las mujeres embarazada multíparas.

De las mujeres embarazadas, el 53\% indicaron que su estado civil es unión libre, el 31\% se han casado. Se establece un gran nivel de mujeres que mantienen una 
relación estable y monogámica de más de dos años con su pareja indicando ser una mujer libre de vínculo matrimonial. Asimismo, el 45\% de las mujeres embarazadas tienen un nivel de estudios hasta secundaria incompleta, mientras que el $38 \%$ manifestó que presenta la secundaria completa. El $48 \%$ de las mujeres embarazadas manifestaron que la edad que tuvo su primera relación sexual fue entre los 16 a 20 años, mientras el 31\% indicaron que antes de los 15 años, el $20 \%$ tuvieron de 21 a 25 y el $1 \%$ oscila entre 26 a 30 años.

\section{RESULTADOS}

Tabla 1

Frecuencia de aseo Íntimo.

\begin{tabular}{ccc}
\hline & $\mathrm{n}$ & $\%$ \\
\hline 1 vez al día & 112 & $55 \%$ \\
2 veces al día & 54 & $26 \%$ \\
3 veces al día & 26 & $13 \%$ \\
más de 4 veces al día & 12 & $6 \%$ \\
Total & 204 & $100 \%$ \\
\hline
\end{tabular}

Se observa en la Tabla 1, que el 55\% índico que una vez al día realiza el aseo íntimo, mientras el 26\% manifestó que dos veces al día se realiza el aseo corres- pondiente, un $13 \%$ que tres veces al día, y el $6 \%$ se realiza el aseo más de 4 veces al día.

Tabla 2

Sintomas de las infecciones de vías urinarias.

\begin{tabular}{ccc}
\hline & $\mathrm{n}$ & $\%$ \\
\hline Dolor Abdominal & 8 & $4 \%$ \\
Estreñimiento & 0 & $0 \%$ \\
Ardor al orinar & 68 & $33 \%$ \\
Orinar a cada momento y en poca & 4 & $2 \%$ \\
cantidad & 0 & $0 \%$ \\
Dolor pélvico & 0 & $0 \%$ \\
Sangre en la orina & 124 & $61 \%$ \\
No tengo conocimiento & 204 & $100 \%$ \\
Total & &
\end{tabular}

Se muestra en la Tabla 2, el $61 \%$ de las mujeres embarazadas manifestaron que no tienen ningún conocimiento base del principal síntoma que genera la infección de vías urinarias, mientras el $33 \%$ consideraron que por el ardor al orinar, el $4 \%$ dicen que por dolor abdominal; por último, el $2 \%$ que orinan a cada momento y en poca cantidad.

Tabla 3

Presencia de retención urinaria.

\begin{tabular}{ccc}
\hline & $\mathrm{n}$ & $\%$ \\
\hline Siempre & 156 & $76 \%$ \\
Nunca & 48 & $24 \%$ \\
Total & 204 & $100 \%$ \\
\hline
\end{tabular}


En la Tabla 3 se evidencia que las mujeres embarazadas en un $76 \%$ manifestaron que con mucha frecuencia se aguanta las ganas de orinar, más que todo, cuando no se encuentran en sus hogares, mientras que el $24 \%$ dicen que nunca se aguantan las ganas de orinar, porque conocen ciertas complicaciones que puede generar.

Tabla 4

Presencia de infección en las vías urinarias.

\begin{tabular}{ccc}
\hline & $\mathrm{n}$ & $\%$ \\
\hline Si presente & 96 & $47 \%$ \\
No presente & 108 & $53 \%$ \\
Total & 204 & $100 \%$ \\
\hline
\end{tabular}

Como se muestra en la Tabla 4 el 53\% de las mujeres embarazadas manifestaron que no han presentado infección en las vías urinarias pero no tienen el conocimiento referente a como se genera lo cual se sienten expuestas a esta patología, mientras el $47 \%$ expresaron que si presentaron IVU.

Tabla 5

Medidas preventivas o tratamientos ante infección de las vías urinarias.

\begin{tabular}{ccc}
\hline & $\mathrm{n}$ & $\%$ \\
\hline Acude al servicio médico & 15 & $7 \%$ \\
Usa remedios caseros & 86 & $42 \%$ \\
Usa remedios que ya conoce & 32 & $16 \%$ \\
Va a la farmacia para que le recomienden algo & 71 & $35 \%$ \\
Total & 204 & $100 \%$ \\
\hline
\end{tabular}

La Tabla 5 presenta al $42 \%$ de las mujeres embarazadas manifestaron las medidas preventivas o tratamientos que ha realizado cuando presenta infección de las vías urinarias es la utilización de remedios caseros; mientras el 35\% se dirige a una farmacia para que le recomienden algún medicamento para la infección, el 16\% utiliza los medicamentos que ya conoce, y un bajo porcentaje de $7 \%$ acuden al servicio médico.

Tabla 6

Controles médicos en infecciones de las vías urinarias.

\begin{tabular}{ccc}
\hline & $\mathrm{n}$ & $\%$ \\
\hline A veces & 98 & $48 \%$ \\
Siempre & 21 & $10 \%$ \\
Ninguno & 85 & $42 \%$ \\
Total & 204 & $100 \%$ \\
\hline
\end{tabular}

En la Tabla 6 se muestra que el $48 \%$ de las mujeres embarazadas que manifestaron que a veces se realizar los controles médicos cuando han tenido infecciones de las vías urinarias, mientras el $42 \%$ expresaron que ningún tratamiento se ha realizado, y por último el $10 \%$ que siempre. 
Tabla 7

Abandonar el cuidado y tratamiento de la infección de vías urinarias por la escasez de recursos económicos.

\begin{tabular}{ccc}
\hline Alternativas & $\mathrm{n}$ & $\%$ \\
\hline Sí & 145 & $71 \%$ \\
No & 59 & $29 \%$ \\
Total & 204 & $100 \%$ \\
\hline
\end{tabular}

Se observa en la Tabla 7 que el $71 \%$ de las mujeres embarazadas indicaron que si algunas veces han tenido que abandonar el cuidado y tratamiento de la infección de vías urinarias por la escasez de recursos económicos, mientras el $29 \%$ manifestaron que no han abandonado el cuidado y tratamiento del IVU.

\section{DISCUSIÓN}

Las infecciones del tracto urinario son las complicaciones más frecuentes de la embarazada. Se presenta en algún momento de la gestación, ocasionando con ello una serie morbilidad materna y perinatal (parto pre término, peso bajo al nacer y ruptura prematura de membranas). Por lo que es muy importante el manejo desde la aparición de una bacteriuria asintomática en estas pacientes. Por esta razón, está incluida dentro de la programación de atención primaria, cuyo objetivo de detección durante el periodo prenatal es disminuir la morbi-mortalidad materno infantil.

En el año 2010, el cuerpo académico Ciencias de la Salud de la Facultad de Medicina de la Benemérita Universidad Autónoma de Puebla (BUAP) del Colegio de Posgraduados, Campus Puebla, en unos de sus artículos originales en su tema denomina "Prevalencia de infecciones de vías urinarias en embarazadas atendidas en el Hospital Universitario de Puebla" en un estudio realizado en 83 mujeres embarazadas (internas y externas) se pudo demostrar en sus variables de estudio tanto edad, trimestre de embarazo, manifestaciones clínicas, método diagnóstico y tratamiento, en las cuales la edad presentó mayor frecuencia de infección urinaria siendo este valor del $27.7 \%$ edad comprendida entre 20 - 24 años y el de menor frecuencia el de $30-34$ años valores de $1.08 \%$, siendo este el germen mayor encontrado en el examen general de orina (EGO) y en el urocultivo fe Echerichia coli; finalmente las afecciones urinarias se presentan según este estudio en el último trimestre de gestación, la prevalencia es de $1.78 \%$, la cual es relativamente baja de acuerdo con la literatura encontrada, y el grupo de edad más vulnerable es de 20-24 años, contrario a lo refiere la literatura, que dice a mayor edad, mayor predisposición a una infección urinaria, atribuyéndose al estado socioeconómico bajo o malos hábitos higiénicos.

Por consiguiente, en el mismo año 2010 se realizó un estudio en 1429 pacientes denominado caracterización de la infección de las vías urinarias en mujeres embarazadas atendidas en una entidad de primer nivel de atención en Manizales, Colombia, como artículo de investigación científica publicado en Red de Revistas Científicas de América Latina, el Caribe, España y Portugal redalyc por medio de la universidad de Manizales, sus resultados del total de mujeres el $36,1 \%$ de las gestantes presentaron IVU de estas el $45,9 \%$ fue detectado en el primer trimestre de edad gestacional, siendo la bacteriuria asintomática la más frecuente con un $9,1 \%$. En un $95,1 \%$ no se encontraron complicaciones asociadas, el paraclínico más utilizado fue el parcial de orina con una frecuencia del $99,9 \%$ las pacientes que presentaron IUV recibieron tratamiento antibiótico con: penicilina sintética 47,7 $\%$ y el $75,2 \%$ no requirieron hospitalización.

Después de haber realizado este respectivo análisis en ambos trabajos realizado hemos podido apreciar la incidencia de bacterias en mujeres gestantes, la prevalencia es de $1.78 \%$, la cual es relativamente baja de acuerdo con la literatura encontrada, y el grupo de edad más vulnerable es de 20-24 años, contrario a lo refiere la literatura, que dice a mayor edad, mayor predisposición a una infección urinaria, atribuyéndose al estado socioeconómico bajo o malos hábitos higiénicos.

Expresa que la bacteriuria asintomática es una de las complicaciones infecciosas más frecuentes del embarazo. La prevalencia de la bacteriuria no cambia con el embarazo y oscila entre el 2 y el $7 \%$. El riesgo de adquirir bacteriuria durante el embarazo aumenta con su duración, la clase socioeconómica más baja, la multiparidad y la anemia drepanocitica. Es probable que el origen de la bacteriuria en las pacientes embarazadas refleje la situación antes de la concepción. Según las estadísticas la incidencia de infecciones de vías urinarias en su mayoría se da por un proceso infeccioso. Siendo esta la causa de complicaciones (Kavoussi. \& Partings, 2008). 
En un estudio de 1429 pacientes denominado caracterización de la infección de las vías urinarias en mujeres embarazadas atendidas en una entidad de primer nivel de atención en Manizales, cuyos resultados del total de mujeres el 36,1\% de las gestantes presentaron IVU de estas el 45,9\% fue detectado en el primer trimestre de edad gestacional; siendo la bacteriuria asintomática la más frecuente con un $9,1 \%$. En un $95,1 \%$ no se encontraron complicaciones asociadas, el paraclínico más utilizado fue el parcial de orina con una frecuencia del $99,9 \%$ las pacientes que presentaron IUV recibieron tratamiento antibiótico con: penicilina sintética 47,7\% y el 75,2\% no requirieron hospitalización.

En el estudio se pretendió retroalimentar las medidas de prevención sobre de la infección de las vías urinarias en las mujeres embarazadas multíparas de la parroquia Siete de Octubre del cantón Quevedo. Ya que estas mujeres presentan de manera fácil infecciones de vías urinarias (IVU) debido a cambios funcionales, hormonales y anatómicos; además de la localización del meato uretral expuesta a bacterias uro patógenas y de vagina que acceden al tracto urinario Echerichia coli es el patógeno más frecuentemente aislado en IVU durante el embarazo, es así como lo muestra la investigación del primer trabajo en Puebla México. 2-3 La relación entre bacteriuria asintomática, parto pre término y peso bajo al nacimiento ha sido bien documentada. 1-2-3-4 Más de $27 \%$ de partos pre término tienen una asociación clínica con IVU, aunque la patogénesis de la contracción uterina aún no está clara. 1-4 El tratamiento adecuado de las infecciones de vías urinarias bajas requiere de un adecuado análisis de las resistencias bacterianas locales a los antibióticos, ya que esta es la principal causa de falla terapéutica.

Las infecciones urinarias la bacterias como la Echerichia coli o colibacilo es el germen más habitual en los uro cultivos de la pacientes afectadas de infección urinaria extra hospitalaria, y las infecciones en las embarazadas no son una excepción a dicha aseveración. La incidencia oscila entre 75 y 90. Con mucha menor frecuencia encontramos Proteus (3-3.5\%) y Klebsiella (1,7-6\%). Aun menos frecuente son Enterobacter, Enterococo, Estreptococo B Y Estafilococo. La responsabilidad del Estreptococo B ha sido cuestionada pues su presencia en los uros cultivos. (L. Cabero. D. Zaldívar. E. Cabrillo. 2007).

En el centro de salud Siete de Octubre el 69\% de las mujeres embarazadas no conocen cuáles son las principales causas por la que se genera la infección, un $100 \%$ de las mujeres de la parroquia Siete de Octubre, indicaron que sí participarían en capacitaciones para conocer los métodos de prevención de la infección de las vías urinarias. El 31\% indicaron que si tienen ciertos conocimientos lo cual han escuchado diversos aspectos referentes a la patología. Al evaluar sobre ¿Cuál de las siguientes opciones cree $\mathrm{Ud}$, que corresponden al principal síntoma de las infecciones de vías urinarias? El 61\% de las mujeres embarazadas manifestaron que no tienen ningún conocimiento base del principal síntoma que genera la infección de vías urinarias. Debido a esto podríamos asumir que las autoridades competente sobre todo las de gobierno local realicen estudios de investigación pura o aplicada para con los sectores ya identificados en este trabajo y así contribuir con campañas de capacitación o vacunación para mitigar o prevenir futuras infecciones de las mujeres embarazas.

\section{Declaración de financiamiento y de conflicto de intereses:}

El estudio fue financiado por los autores, quienes declaran no tener algún tipo de conflicto de interés en la investigación realizada.

\section{Correspondencia:}

Lourdes Bello.

Facultad de Enfermería, Universidad Laica Eloy Alfaro de Manabí,. Cdla. Universitaria Vía a San Mateo, Teléfono 2628825 - 2623740 Ext.196- Ecuador Manabí Manta.

e-mail: lourdesbello2009@hotmail.com. lourdes.be1lo@uleam.edu.ec.

\section{REFERENCIAS BIBLIOGRÁFICAS}

Ahued R. Fernández C. Bailón R. (2003). Ginecología y Obstetricia Aplicadas. Ed. El Manual Moderno MéxicoSanta Fe Bogotá. Pg 501.

Álvarez, G. Cruz, J. Garau, A. (2006), Infección Urinaria y Embarazo. Diagnóstico y Terapéutica. Revista de Posgrado de la VI a Cátedra de Medicina. No 155. 20$23 \mathrm{p}$.

Arias Fernando (2008). Guía práctica para el embarazo y parto de alto riesgo. 2 da Edición. Edit. Harcourt Brace.

Cabero Roura L. (2004). Parto Prematuro. Vol Edit. Panamericana.

Cabero. D. Saldívar. E. Cabrillo (2007). Obstetricia y Medicina Materno -Fetal. Ed. Médica Panamericana. Buenos Aires-Bogotá-Caracas-Madrid-México-Porto Alegre. Pg. 831.

Casteiazo L. (2007). Resnik Robert MD Maternal fetal medicine principles and practice. Fifth edition. Saunders. 
Dalet F. \& Gerardo Del Rio (1998). Infecciones Urinarias. Ed. Médica Panamericana. España. Pg 15.

Ferreira F. (2005). Infección Urinaria Durante el Embarazo, Perfil de Resistencia Bacteriana al Tratamiento en el Hospital General de Neiva, Colombia. Revista Colombiana de Obstetricia y Ginecología, No 56 (3). $239-243 \mathrm{p}$.

Ferreira F. (2007). Infección Urinaria Durante el Embarazo, Perfil de Resistencia Bacteriana al Tratamiento en el Hospital General de Neiva, Colombia. Revista Colombiana de Obstetricia y Ginecología. No 56 (3). $239-243 \mathrm{p}$.

Gonzales Merlo, J. (1988). Ginecología. 5 ed. Barcelona: Salvat Editores S.A, 1.

Gutiérrez A. (2007). Medicina Interna. 13va. Edición. Infección de vías urinarias. Pag. 780786.

Iriarte, C. (2006) Parto Pre término en Pacientes del Hospital San Juan de Dios Universidad Privada del Valle. OruroBolivia.

Jacques, W. (2003). Clínica de las Pruebas de Laboratorio. 1 ed. España: Masson. 949 -999 p.

Lincoln Ivonne (2009). Obstetricia clínica / Clínica Obstetrics. Ed. Médica Panamericana.

Ministerio de Salud Pública del Ecuador. (2008). Infección de Vias Urinarias en el Embarazo. Componente Normativo Materno. Agosto: 59 - 68 p.

Niswander K. (1987). Obstetricia Práctica Clínica. Ed. Reverte S. A. Barcelona-Bogotá-Buenos Aires-CaracasMéxico. Pg 89

Oppermann, S. Hans (2005). Infección urinaria en el embarazo tratamientos acortados vs. Tratamientos prolongados tradicionales. Fronteras en Obstetricia y Ginecología. Dic. 2005; 2(2): Pág. 33.
Paredes, M. (2008). Determinantes de Riesgo Obstétrico y Perinatal que Aumentan la Incidencia de Parto: Una Visión Epidemiológica en el Embarazo de Mujeres. Tesis de Pregrado previa a la obtención del Título de Médico General. Riobamba - Ecuador. 40 - 59 p.

Prats Guillem (2006). Microbiología Clínica, Ed. Médica Panamericana, Buenos Aires.

Quiroga, G. Robles, R. Ruelas, A. Gómez, A. (2007). Bacteriuria Asintomática en Mujeres Embarazadas. Revista Médica del Instituto Mexicano de Seguridad Social. No 45(2). 169-172 p.

Robles, R. Ruelas, A. Gómez, A. Bacteriuria Asintomática en Mujeres Embarazadas. Revista Médica del Instituto Mexicano de Seguridad Social. 2007. No 45(2). 169-172 p.

Silva S. Hernán (1991). Medicina Legal y psiquiátrica, tomo I, Ed. Jurídica de Chile, Santiago de Chile.

Vázquez, J. Villar, J. (2008). Tratamientos para las Infecciones Urinarias Sintomáticas Durante el Embarazo (Revisión Cochrane traducida). En: La Bibliotheca Cochrane Plus. No 2. Oxford: Update Software Ltd.

Wein.Kavoussi.Novick.Partin, Peters. (2008). CampbellWalsh Urología. Ed. Panamericano Buenos AiresBogotá- Caracas-Madrid-México- Porto Alegre. Pg 291.

Williams (2006). Obstetricia. 22 ed. México, 15 - 39 p. 1093 $-1111 \mathrm{p}$.

Yánez N. (1998). Perfiles Epidemiológicos de la Madre de Recién Nacido Prematuro en el Hospital GinecoObstétrico Isidro Ayora de Quito. Revista Ecuatoriana de Pediatría. Septiembre, 12 - 16 p.

Recibido: 17/06/2016 Aceptado: 05/04/2017 